\title{
Curricularização da extensão universitária: práticas de extensão realizadas no Curso de Letras - Língua Portuguesa durante a pandemia
}

\section{Curricularization of university extension: extension activities performed in Portuguese Language and Literature undergraduate course during the pandemic}

\author{
Kleber Eckert ${ }^{1}$ \\ Carina Fior Postingher Balzan² \\ Priscila Ogliari Mariani ${ }^{3}$ \\ Aline Almeida de Lemos ${ }^{4}$ \\ Esther de Paula Guedes ${ }^{5}$ \\ Hamilton Ornes Bitencourt Junior 6
}

\begin{abstract}
Resumo
O presente trabalho busca relatar as experiências de extensão realizadas no componente curricular de "Estágio Supervisionado - Projetos de Extensão", inserido no Curso de Licenciatura em Letras - Língua Portuguesa, no Instituto Federal de Educação, Ciência e Tecnologia do Rio Grande do Sul campus Bento Gonçalves. As atividades realizadas envolveram planejamento e atuação em dois projetos de extensão do campus. O primeiro, a VI Semana de Língua e Literatura no campus, promoveu palestras, a respeito de temas vinculados ao ENEM e vestibulares, voltadas para a preparação dos alunos do Ensino Médio para essas provas. O segundo, o Curso de Português para imigrantes e refugiados, promoveu aulas de português para esse perfil de alunos, sob a perspectiva da Língua de Acolhimento. $O$ objetivo deste relato é relacionar as práticas de extensão realizadas à proposta da curricularização da extensão, a fim de destacar a contribuição da extensão na formação dos sujeitos e na sociedade em que se insere e, portanto, a relevância da realização dessas atividades. Ainda, as ações de extensão aqui descritas foram realizadas em contexto pandêmico, portanto, também será objeto de reflexão o papel da extensão no sentido de mitigar os efeitos deletérios da pandemia de COVID-19 no ensino.
\end{abstract}

Palavras-chave: Extensão universitária. Graduação em Letras. Contexto pandêmico.

\begin{abstract}
This report describes the university extension experiences performed during the curricular component of "Estágio Supervisionado - Projetos de Extensão", offered by Portuguese Language and Literature undergraduate course at Instituto Federal de Educação, Ciência e Tecnologia do Rio Grande do Sul campus Bento Gonçalves. The activities performed included planning and teaching in two extension projects of the campus. The first one, VI Semana de Língua e Literatura no campus, provided lessons on topics related to ENEM and University Entrance Examinations focusing on preparing high school students

\footnotetext{
1 Doutor em Letras. Instituto Federal de Educação, Ciência e Tecnologia do Rio Grande do Sul - IFRS, Bento Gonçalves, Rio Grande do Sul, Brasil. Orcid: orcid.org/0000-0002-6436-1193 E-mail: kleber.eckert@bento.ifrs.edu.br

2 Doutora em Letras. Instituto Federal de Educação, Ciência e Tecnologia do Rio Grande do Sul - IFRS, Bento Gonçalves, Rio Grande do Sul, Brasil. Orcid: orcid.org/0000-0002-5127-1471 E-mai: carina.balzan@bento.ifrs.edu.br

3 Graduanda em Letras. Instituto Federal de Educação, Ciência e Tecnologia do Rio Grande do Sul - IFRS, Bento Gonçalves, Rio Grande do Sul, Brasil. Orcid: orcid.org/0000-0002-0124-4379 E-mail: prisciogliari@gmail.com

${ }^{4}$ Graduanda em Letras. Instituto Federal de Educação, Ciência e Tecnologia do Rio Grande do Sul - IFRS, Bento Gonçalves, Rio Grande do Sul, Brasil. Orcid: orcid.org/0000-0002-4003-776X E-mail: alinelemos.d@hotmail.com

5 Graduanda em Letras. Instituto Federal de Educação, Ciência e Tecnologia do Rio Grande do Sul - IFRS, Bento Gonçalves, Rio Grande do Sul, Brasil. Orcid: orcid.org/0000-0001-8661-5193 E-mail: estherguedes99@gmail.com

6 Graduando em Letras. Instituto Federal de Educação, Ciência e Tecnologia do Rio Grande do Sul - IFRS, Bento

Gonçalves, Rio Grande do Sul, Brasil. Orcid: orcid.org/0000-0002-4280-2074 E-mail: hamiltonbitencourt2000@gmail.com
} 
for these exams. The second, Curso de Português para imigrantes e refugiados, provided Portuguese lessons to immigrants and refugees, on the perspective of the Portuguese as a Host Language. The aim of this study is to relate the extension activities performed to the propositions of the curricularization of university extension, in order to highlight the contributions of the extension projects on the undergraduate students and on the society in which it operates, and, thus, the relevance of these activities. In addition, the projects described in this report took place during the COVID-19 pandemic, therefore, the role of the university extension when it comes to mitigating harmful effects of the pandemic in education will also be analyzed.

Keywords: University extension. Undergraduate degree in Language and Literature. Pandemic.

\section{Extensão universitária: uma introdução}

As primeiras experiências de extensão universitária no Brasil datam do início do século XX. Entre os anos de 1911 e 1917, foram realizadas diversas atividades de cunho extensionista na Universidade Livre de São Paulo. A instituição permitia a participação do público em geral em eventos e conferências, os quais tratavam das mais diferentes temáticas. Nesse período, ainda não havia uma estreita relação, como há hoje, entre extensão universitária e resolução de problemas sociais. Somente no ano de 1931, com o Decreto do "Estatuto da Universidade Brasileira", a extensão universitária passou a ter um compromisso verdadeiramente social (ABRANCHES, 2014, p. 41).

A partir da apresentação do Decreto, diferentes instituições de ensino procuraram desenvolver novos projetos que pudessem, de fato, estar relacionados com o compromisso da extensão. Hoje, no entanto, sabemos que muitos desses projetos tinham caráter assistencialista e não reivindicavam a emancipação dos sujeitos envolvidos. Ao longo da ditadura militar, projetos de extensão perderam força e, somente após a decaída do regime, eles começaram a se estruturar novamente e com maior consistência nas mais diversas instituições de ensino. Segundo Abranches (2014):

Em 1968, após a Reforma Universitária e com o advento do Regime Militar no governo, a extensão universitária perde sua força de expansão e de interação com a sociedade, mas não o seu caráter crítico, ainda que a extensão universitária estivesse, nas décadas de 70 e 80 , voltada para a execução de políticas sociais do governo. (ABRANCHES, 2014, p. 41).

No final dos anos 1980 e início dos anos 1990, a extensão universitária sofreu mudanças significativas. O caráter assistencialista dos projetos passou, paulatinamente, a ser deixado de lado e, através de uma série de publicações e orientações sobre o tema, a extensão universitária mudou completamente de fisionomia. Documentos como o Plano Nacional de Extensão Universitária foram os grandes responsáveis por essa mudança de direção (ABRANCHES, 2014, p. 41-42). Hoje, as Diretrizes Curriculares Nacionais para a formação inicial de professores em nível superior (BRASIL, 2015) esclarecem que a extensão universitária é um princípio pedagógico essencial ao aprimoramento do profissional da prática educativa. Ela está articulada ao ensino e à pesquisa e tem o compromisso 
principal de estabelecer um vínculo entre determinada instituição educativa e a comunidade intra ou extraescolar. Segundo Cristofoli e Silva (2014):

Institucionalmente ampliam-se as discussões sobre o financiamento da extensão, formas de operacionalização a partir de diretrizes nacionais, creditação curricular, publicações com maior reconhecimento, valorização do docente extensionista por meio do plano de carreira, mensuração dos resultados e da avaliação da extensão, entre outros. (CRISTOFOLI; SILVA, 2014, p. 11-12).

Diante do que foi exposto, podemos entender que a extensão deve estar relacionada às demandas sociais, políticas, econômicas e culturais de uma comunidade. Nesse sentido, podemos afirmar que a extensão universitária assume um papel bastante significativo na formação acadêmica de futuros profissionais e na resolução de problemas de ordem social. As Diretrizes Curriculares Nacionais (BRASIL, 2015), no capítulo I, Art. $4^{\circ}$, apontam, como princípio para garantir efetivo padrão de qualidade acadêmica na formação dos profissionais da educação, a articulação entre a teoria e a prática no processo de formação docente, que se funda no domínio dos conhecimentos científicos e didáticos e contempla a indissociabilidade entre ensino, pesquisa e extensão. De acordo com Abranches (2014):

A extensão universitária, no país, vem desempenhando um papel importante tanto na formação acadêmica de futuros profissionais quanto no atendimento aos desafios sociais, políticos e econômicos da sociedade por meio de vocação para a sistematização de ideias e a produção de conhecimento. (ABRANCHES, 2014, p. 39).

No que diz respeito ao currículo, no capítulo V das Diretrizes Curriculares Nacionais (BRASIL, 2015), está previsto que a formação inicial do magistério da educação básica em nível superior, além do mínimo de 3.200 horas de efetivo trabalho acadêmico, deve compreender 200 horas de atividades teórico-práticas, que deverão se dar, entre outros, também no âmbito da extensão. Nesse sentido, 0 currículo do curso de Licenciatura em Letras - Língua Portuguesa, ofertado no IFRS campus Bento Gonçalves, que foi formulado em 2017, já teve seu Projeto Pedagógico elaborado de modo a contemplar a centralidade da extensão em sua estrutura curricular, conforme preconizado nas Diretrizes Curriculares Nacionais. As práticas de extensão previstas estão vinculadas não só às atividades curriculares complementares, mas também fazem parte da própria grade curricular do curso e são desenvolvidas como requisito de um Estágio Curricular Obrigatório. Conforme encontra-se no Projeto Pedagógico do Curso: 
componentes curriculares do curso foram planejados e organizados de modo a proporcionar a formação de um profissional para a docência na Educação Básica e Profissional, capaz de refletir acerca das questões que permeiam 0 ensino de língua e literatura e atuar como pesquisador de sua própria prática profissional em sala de aula. Destaca-se, também, a indissociabilidade entre as dimensões de ensino, pesquisa e extensão, que embasa a construção deste Projeto de Curso e perpassa toda a sua estrutura curricular. (IFRS, 2017, p. 09-10).

Dessa forma, o componente curricular de "Estágio Supervisionado - Projetos de Extensão", ofertado no $5^{\circ}$ semestre do curso, tem o objetivo principal de inserir os alunos em práticas de extensão, e os conteúdos da disciplina incluem temáticas vinculadas à extensão no contexto do país e da região. Figuram entre elas conhecer a natureza da extensão universitária, o histórico da extensão universitária no Brasil, a relação ensino-pesquisa-extensão e a extensão no IFRS e no campus Bento Gonçalves. Além disso, conhecer, desenvolver e atuar em projetos de extensão na área de Letras desenvolvidos no campus, a saber, a Semana de Língua e Literatura no campus e o Curso de Língua Portuguesa para imigrantes e refugiados. Ao final, também compreende a produção acadêmica na área de extensão, e este relato de experiência é parte da proposta da disciplina e é produto dela.

A partir das discussões sobre os projetos de extensão na área de Letras e do estudo dos conteúdos relacionados a eles, os estudantes do Curso de Licenciatura em Letras foram incumbidos de elaborar e executar dois projetos de extensão. Por se tratar de projetos de extensão, é inevitável que eles estabeleçam vínculos entre a instituição educativa e a comunidade intra e/ou extraescolar. 0 desenvolvimento dos projetos deve, portanto, responder a uma necessidade social, visto que a extensão universitária do nosso país tem esse compromisso.

O presente trabalho tem o objetivo de relatar as práticas desenvolvidas na disciplina de "Estágio Supervisionado - Projetos de Extensão", especialmente as experiências vivenciadas na execução dos projetos, que envolveram a elaboração e desenvolvimento das atividades, mas se distinguem por perpassar a adaptação ao ensino remoto e às tecnologias digitais, em função do contexto pandêmico, e evocar a reflexão sobre as implicações desse contexto nas atividades de extensão. Para tanto, será realizado o relato dos dois grandes projetos do componente: a Semana de Língua e Literatura no campus e o Curso de Língua Portuguesa para imigrantes e refugiados.

\section{VI Semana de Língua e Literatura no campus}

A Semana de Língua e Literatura no campus é realizada anualmente no IFRS campus Bento Gonçalves desde 2015. Em suas primeiras cinco edições (de 2015 a 2019), teve suas atividades coordenadas e conduzidas por docentes da área de Letras do campus. A proposta do evento é oferecer 
palestras e oficinas a estudantes do Ensino Médio, sobretudo do terceiro ano; contudo, também é aberto a estudantes do Ensino Superior e a professores da Educação Básica e demais interessados nos temas abordados.

O evento é vinculado ao Programa de Extensão Línguas e Literaturas no Campus (PRELLIC), um programa que reúne diversas iniciativas de extensão - como cursos, eventos, palestras e oficinas — na área de Letras. O propósito do Programa é promover ações de extensão que integrem as atividades institucionais voltadas ao ensino das línguas e literaturas à comunidade intra e extraescolar, de forma a articular de maneira prática o compromisso da instituição e do Curso de Letras - que dialoga, conforme mencionado na introdução deste trabalho, com as Diretrizes Curriculares Nacionais dos Cursos de Licenciatura - com as necessidades e demandas sociais no que tange à formação literária e linguística, sob uma perspectiva crítica e reflexiva.

No ano de 2021, o evento teve sua sexta edição. Foi realizado entre 09 e 12 de agosto, das $19 \mathrm{~h} 30$ às $21 \mathrm{~h}$, com duas atividades de 45 minutos por noite, e ocorreu de forma remota, com a utilização da plataforma Zoom e transmissão pelo canal do Youtube do campus Bento Gonçalves ${ }^{7}$. Como neste ano o evento estava vinculado ao componente curricular "Estágio Supervisionado - Projetos de Extensão", foram os estudantes da graduação matriculados no componente curricular, sob orientação e supervisão dos professores da disciplina, que ficaram responsáveis por organizar e conduzir o evento.

Em um primeiro momento, os estudantes decidiram quais seriam os temas das palestras, que seriam realizadas em duplas, e foi organizado o cronograma das apresentações, que seria utilizado para confecção do material de divulgação. Em diálogo com a proposta do programa de extensão em que se insere 0 evento, foram propostas palestras que abordaram a análise literária e linguística e a escrita, sempre em uma perspectiva relacionada à preparação para o ENEM e Vestibulares. Foram ministradas sete palestras. No primeiro dia, o evento contou com uma abertura e a palestra "Memórias Póstumas de Brás Cubas, de Machado de Assis: leitura obrigatória para o ENEM"; no segundo dia, as palestras foram "Idas e vindas do texto: a microestrutura textual nas questões do ENEM" e "O uso da vírgula na redação do ENEM/Vestibular"; no terceiro dia, as palestras foram "A língua em movimento: variação linguística nas questões do ENEM" e "Redação do ENEM: a macroestrutura do texto"; e, no último dia, as palestras foram "Vidas Secas, de Graciliano Ramos: análise de questões do ENEM e de vestibular" e "Vestibular UFRGS - As meninas, de Lygia Fagundes Telles: análise da obra e de questões de vestibular".

\footnotetext{
${ }^{7}$ As transmissões ao vivo ficaram gravadas e podem ser acessadas através destes links: 6 a Semana de Língua e Literatura

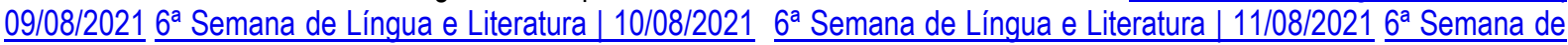
Língua e Literatura | 12/08/2021
}

LínguaTec, Instituto Federal de Educação, Ciência e Tecnologia do Rio Grande do Sul, Bento Gonçalves 
Além da organização das palestras e da preparação das apresentações, os estudantes também ficaram responsáveis pela divulgação do evento. A divulgação contou com o apoio do Setor de Comunicação Social do campus Bento Gonçalves, ligado à Diretoria de Extensão, que confeccionou os materiais de divulgação. $O$ setor de Comunicação também coordenou a transmissão do evento, que foi feita ao vivo pelo canal de Youtube do campus. Em posse dos materiais, os estudantes ficaram encarregados de entrar em contato com escolas de Ensino Médio da região para divulgar o evento aos alunos e professores.

Após a realização do evento, como parte da avaliação do componente curricular, os estudantes redigiram um memorial avaliativo sobre a experiência de extensão realizada. A escrita do memorial possibilitou uma reflexão sobre a condução das atividades e do evento como um todo.

É importante destacar o forte papel formador e instrumentalizador do evento na trajetória acadêmica dos licenciandos participantes. Para além da oportunidade de elaborar e ministrar uma palestra no evento, ofereceu uma experiência de contato com a organização e viabilização de atividades na área da extensão universitária. Essa experiência é de grande significado aos futuros profissionais da educação, que estarão melhor preparados para colaborar ou mesmo coordenar atividades de extensão futuramente. Ainda, ofereceu aos alunos a oportunidade de aprender a lidar ou aperfeiçoar seus conhecimentos relacionados ao uso das tecnologias digitais, uma vez que foi necessária a adaptação do evento a essas tecnologias, que tendem a ter uso crescente nos próximos anos.

Além da contribuição à formação dos estudantes envolvidos na realização do evento, destacamos também a importância dele no sentido de desenvolver palestras destinadas à compreensão e resolução de questões de ENEM e Vestibular, além da elaboração da redação, que têm extrema relevância ao público-alvo que deseja ingressar no Ensino Superior. Ademais, é necessário atentar para a contribuição do evento para a formação público-alvo, haja vista que já vivíamos um contexto de grande carência no sistema educacional da rede pública, e essa carência foi severamente agravada pelos efeitos da pandemia de COVID-19 na Educação Básica brasileira. Nesse sentido, o evento surge como uma tentativa de diminuir as diferenças sociais e de acesso à educação e uma possibilidade de mitigar esses prejuízos, proporcionando aos alunos do Ensino Médio, através da extensão, um contato com 0 conhecimento acadêmico e incentivo ao estudo.

\section{Curso de Extensão Língua Portuguesa para imigrantes e refugiados}

O Curso de Língua Portuguesa para imigrantes e refugiados teve início em 2013 no IFRS, campus Bento Gonçalves, e integra um projeto de extensão ofertado pela instituição. Entende-se por 
extensão a área que procura manter vínculos entre universidade e sociedade. Anteriormente mencionado, Abranches (2014, p. 39) explana a respeito da extensão universitária e sobre seu papel "na formação acadêmica de futuros profissionais quanto no atendimento aos desafios sociais, políticos e econômicos da sociedade por meio de vocação para a sistematização de ideias e a produção de conhecimento".

Dessa forma, observaram-se as demandas emergentes que circundam os meios sociais de diversas regiões, especialmente, da Serra Gaúcha, onde está inserido o campus Bento Gonçalves. Silva e Costa (2020, p. 132) questionam "sobre como inserir pessoas que foram deslocadas predominantemente à força de seus países e que se encontram em condições de vulnerabilidade, em lugares onde nunca imaginaram e/ou desejaram estar?". Nesse sentido, o Curso de Extensão surge com o objetivo de promover a comunicação dos imigrantes e dos refugiados diante de diferentes situações cotidianas, tais como: apresentar-se, realizar compras, pedir e/ou dar informações, buscar atendimento médico, procurar emprego, etc., auxiliando-os no processo de integração à sociedade brasileira. É preciso possibilitar, como explicam Silva e Costa (2020, p. 132), "condições de pertencimento a essas pessoas, uma vez que elas não têm autonomia linguística para re-existir na sociedade que as 'acolheu'.

A perspectiva de ensino de Português como Língua de Acolhimento (PLAc) contempla as necessidades de aprendizagem desse público ao mesmo tempo em que valoriza o repertório linguístico e cultural dessas pessoas deslocadas forçadas. Conforme explica Costa (2017):

\begin{abstract}
Língua de Acolhimento $(\mathrm{LAc})$ refere-se à aprendizagem de língua não materna em contexto migratório, cujo principal fim é a integração à sociedade de acolhimento. O PLAc destina-se a imigrantes e refugiados, transplantados de outros territórios, provenientes de regiões em situação de precariedade econômica, política ou social, cujas possibilidades de (sobre)vivência encontram-se negativamente mais complexas que as dos países receptores, impossibilitando uma vida em condições seguras. À mobilidade forçada acrescenta-se a fragilidade das escolhas realizadas no percurso de migração, um processo muitas vezes realizado às pressas e sem planejamento, em caráter de urgência. Tal conceito transcende a perspectiva linguística e cultural e refere-se também ao caráter emocional e subjetivo da língua e à relação conflituosa presente no contato inicial do imigrante com a sociedade de acolhimento, a julgar pela situação de vulnerabilidade que essas pessoas enfrentam. (COSTA, 2017, p. 244).
\end{abstract}

Nesse sentido, essa perspectiva, mais crítica e construtiva, norteou a abordagem acerca do ensino de português para imigrantes e refugiados. Em 2018, o Curso de Extensão do IFRS - campus Bento Gonçalves passou por reformulações teóricas e metodológicas, as quais visaram adequar a proposta ao PLAc. Nesse momento, uma das (res)significações pensadas foi a própria nomenclatura do 
curso, de "Curso de Língua Portuguesa para estrangeiros" passou para "Curso de Língua Portuguesa para imigrantes e refugiados".

O Curso de Língua Portuguesa, de nível básico, prioriza situações reais de interação social, atendendo às necessidades trazidas pelos próprios participantes e enfatizando a oralidade. Além disso, a produção dos materiais didáticos prioriza a utilização de materiais autênticos, por estarem mais presentes na vida cotidiana dos estudantes. Assim, gêneros textuais como cartazes, anúncios, panfletos, são bastante utilizados, pois constituem textos que circulam socialmente. ${ }^{8}$

Com carga horária de 30 horas, o Curso de Língua Portuguesa para imigrantes e refugiados ocorria semanalmente nos turnos vespertino e noturno nas dependências do campus Bento Gonçalves. Porém, devido à pandemia de COVID-19, o Curso, assim como outras atividades presenciais da instituição, foram suspensas. A retomada das aulas do Curso ocorreu apenas em 2021, mas em um formato diferente do que estava consolidado. Assim, o Curso foi retomado no formato de ensino remoto, mantendo-se a mesma carga horária.

Diferentemente das edições anteriores, além de ter ocorrido de forma on-line, neste ano, o Curso foi ministrado pelos estudantes do Curso de Letras, dentro do componente "Estágio Supervisionado Projetos de Extensão", sob a orientação e supervisão dos professores da disciplina. Para tanto, os estudantes estagiários receberam embasamento teórico e prático antes da realização do estágio. Inicialmente, estudou-se o que é extensão, importância, dimensão acadêmica e contexto externo. Também foram realizadas leituras teóricas e discussões a respeito do ensino de português para imigrantes e refugiados, sobretudo na perspectiva de PLAc. Posteriormente, foi feito o planejamento das aulas, elaboração do material didático para as aulas síncronas e elaboração de material de apoio e atividades para as atividades assíncronas.

Todo o processo de planejamento das aulas e elaboração de materiais didáticos foi supervisionado pelos professores do estágio através de orientações previamente agendadas, as quais nortearam os ajustes necessários para uma prática de ensino plena. Os estudantes estagiários também realizaram ensaios das aulas (entre suas duplas). Esses momentos foram fundamentais para precisar 0 tempo, a qualidade do planejamento e dos materiais elaborados, e analisar a entonação e a clareza da voz ao comunicar-se com o público-alvo.

A prática dos estudantes estagiários ocorreu em duplas. O Curso de Língua Portuguesa para imigrantes e refugiados ocorreu no período de 09 de junho a 15 de setembro de 2021, às quartas-feiras,

\footnotetext{
8 É possível conhecer um pouco mais sobre o Projeto de Extensão neste vídeo, que traz uma síntese a respeito das informações do projeto: Curso de Língua Portuguesa para imigrantes e refugiados.
} 
das $19 \mathrm{~h}$ às $20 \mathrm{~h}$, totalizando quinze (15) horas de atividades síncronas e quinze (15) horas de atividades assíncronas, e contou com a participação de 50 (cinquenta) imigrantes/refugiados de diferentes nacionalidades, principalmente, do Haiti, de Bangladesh e da Síria.

A primeira aula, ministrada pela coordenadora do Projeto de Extensão, foi para dar as boasvindas aos participantes e passar-lhes informações sobre o funcionamento do curso, certificados e assuntos gerais. A partir da segunda aula, os estudantes estagiários do curso de Letras passaram a ser os condutores das aulas. Cada dupla ficou responsável pelo planejamento de duas horas de atividades síncronas e duas horas de atividades assíncronas. Para as aulas síncronas, foi necessário preparar uma apresentação de slides para melhor organização e explanação, além de ajudar na visualização e compreensão por parte dos participantes do curso. Já para as atividades assíncronas, elaborou-se um material de apoio, enviado aos participantes logo após a aula síncrona via WhatsApp, constituído pelo conteúdo das aulas e atividades de fixação dos tópicos estudados.

As aulas síncronas ocorreram pelo Google Meet, plataforma de videoconferências do Google. Foi um momento de adaptação para todos, tanto para os estudantes estagiários do Curso de Letras, como para os alunos imigrantes e refugiados. Entender como a plataforma funciona, como comunicarse nela, como digitar, entre outras práticas, são exemplos de construções que ocorreram aos poucos para a plena realização e efetivação do Curso de Extensão. Depois do planejamento de duas aulas, de dois materiais didáticos e da condução de duas aulas do curso pelas duplas, os estudantes estagiários escreveram, ainda, um memorial avaliativo, a fim de refletir sobre a realização da prática docente no Curso de Língua Portuguesa para imigrantes e refugiados.

É essencial reconhecer como essa prática ampliou a formação dos estudantes de Letras, não só através da oportunidade de compreender o mundo da extensão, mas também de vivenciar na prática a relação entre universidade e sociedade. Além disso, trouxe aos estudantes a oportunidade de desenvolverem habilidades de ensino e promoverem uma aprendizagem que inclua a todos, no sentido de identificar as particularidades do seu público e encontrar a melhor forma de alcançá-lo. Por fim, possibilitou aos licenciandos reconhecerem a dimensão de ensino e de língua, de forma a enriquecer suas experiências com o ensino de português para imigrantes e refugiados para que estejam preparados para acolher e orientar melhor seus futuros alunos, visto que a presença de estudantes oriundos de migrações forçadas é uma realidade cada vez mais presente nas escolas brasileiras. 


\section{Considerações finais}

Findadas as práticas realizadas ao longo do "Estágio Supervisionado - Projetos de Extensão", é notável como a proposta e o desenvolvimento do componente curricular se articulam aos propósitos da extensão universitária. No que tange ao "papel da universidade enquanto produtora de conhecimento útil para a transformação da sociedade" (CRISTOFOLI; SILVA, 2014, p. 11), podemos destacar a efetividade do componente curricular tanto por sua contribuição na formação acadêmica dos estudantes de Letras, quanto pelo impacto nas populações-alvo dos projetos. As atividades proporcionaram a penetração em camadas da sociedade externas à academia, que puderam ter contato com o conhecimento desenvolvido nesse espaço, de forma a promover a interação social e transformar o ensino e a pesquisa em algo que contribuísse para as comunidades participantes em suas necessidades, que é o cerne da extensão universitária.

A realização da prática de estágio contribuiu para uma formação de excelência dos estudantes do Curso de Licenciatura em Letras do IFRS, campus Bento Gonçalves, na medida em que proporcionou uma experiência diferenciada dentro de sua formação acadêmica, que contribuirá para sua atuação enquanto futuros profissionais da educação. Os estudantes estagiários, que foram provocados a atuar ativamente no desenvolvimento das ações de extensão supramencionadas, estarão mais preparados para participar e mesmo desenvolver atividades e eventos de extensão ao longo de sua futura carreira docente. Mesmo as limitações impostas pelo contexto pandêmico se converteram em experiências de aprendizado ímpares, no sentido de que as habilidades desenvolvidas em relação à adequação ao uso das tecnologias digitais para viabilização dos eventos - desde o uso da plataforma do Google Meet para realização das aulas do Curso de Língua Portuguesa para imigrantes e refugiados ao uso das plataformas Zoom e Youtube para transmissão ao vivo da VI Semana de Língua e Literatura no campus —, que, além de necessárias nesse período, certamente se manterão ferramentas valiosas no futuro da educação e da sociedade como um todo.

No contexto da VI Semana de Língua e Literatura no campus, é válido apontar a importante contribuição para a formação docente, uma vez que os alunos de Letras ficaram responsáveis pela organização das apresentações que foram feitas no evento, pela divulgação do evento e elaboração das palestras. Essa experiência é de grande relevância para a autonomia dos licenciandos na medida em que os instrumentaliza e, por isso, possibilita o protagonismo no desenvolvimento futuro de outras atividades de caráter extensionista.

Além disso, o evento também impactou o público que assistiu às apresentações. Destacamos a relevância da Semana para a formação dos alunos de Ensino Médio, sobretudo dos alunos de escolas 
públicas, que tiveram mais dificuldade de acesso às aulas e de se preparar para os vestibulares e ENEM em função das limitações impostas pelo contexto pandêmico. Dessa forma, a atividade, além do caráter formador, que já vinha exercendo nas outras edições do evento, também teve o papel de mitigar os efeitos deletérios da pandemia e representou uma tentativa de diminuir as diferenças sociais e de acesso à educação.

No que diz respeito ao Curso de Língua Portuguesa para imigrantes e refugiados, a prática de extensão instrumentalizou os licenciandos para lidar com contextos de ensino remoto e de ensino de língua nas escolas que recebem estudantes imigrantes e refugiados. Uma vez que as aulas do curso foram todas realizadas de maneira remota, os estudantes estagiários precisaram aprender a adequar as metodologias de ensino, de interação com os alunos e de elaboração de materiais didáticos às ferramentas digitais. Além disso, estarão melhor preparados para a atuação nas escolas e para lidar com diversas situações, desde contextos que envolvam alunos com esse perfil, até a possibilidade de oferecer oficinas de ensino de Português, na perspectiva da Língua de Acolhimento, aos pais dessas crianças, e mesmo à comunidade escolar em geral, que não dominem o idioma. A relevância dessa experiência na formação docente é inquestionável, dada a realidade da região, que recebeu uma grande população de deslocados forçados nos últimos anos, pessoas que agora compõem nosso quadro social e que, por isso, têm o direito de encontrar profissionais preparados para acolhê-los e oferecer o suporte necessário. As ações de extensão são o ambiente ideal para promover esse tipo de formação e interação.

Ainda, vale destacar a relação dessa ação de extensão ao próprio propósito da extensão universitária de "melhoria das condições de vida e trabalho" (CAPUTO; TEIXEIRA, 2014, p. 10). Os participantes do Curso de Língua Portuguesa para imigrantes e refugiados, através da aprendizagem da língua portuguesa, tiveram acesso à possibilidade de expandir seus horizontes de oportunidades de trabalho e convivência em sociedade, viabilizadas pelo uso da língua.

A inserção das práticas de extensão no currículo universitário é relativamente recente, mas 0 presente relato nos leva a perceber, enfim, a importância de sua realização, não só como atividade complementar, mas também como parte da grade curricular. A extensão se mostra essencial para 0 aprimoramento profissional dos graduandos, mas também para viabilizar uma postura mais dinâmica da universidade perante as demandas e necessidades da sociedade em que se insere.

\section{Referências}

ABRANCHES, M. Política Nacional de Extensão Universitária - 2012: identidade e diretriz para a prática extensionista no ensino superior brasileiro. In: SILVA, L. D.; CÂNDIDO, J. G. (Org.). Extensão 
universitária: conceitos, propostas e provocações. São Bernardo do Campo: SP: Universidade Metodista de São Paulo, 2014. p. 39-45.

BRASIL. Diretrizes Curriculares Nacionais. Brasilia: MEC, 2015. Disponível em: $<$ http://portal.mec.gov.br/docman/agosto-2017-pdf/70431-res-cne-cp-002-03072015-pdf/file>. Acesso em: 12 set. 2021.

CAPUTO, M. C.; TEIXEIRA, C. F. (Org.). Universidade e Sociedade: concepções e projetos de extensão universitária. Salvador: EDUFBA, 2014.

CRISTOFOLI, F.; SILVA, C. D. Introdução. In: SILVA, L. D.; CÂNDIDO, J. G. (Org.). Extensão universitária: conceitos, propostas e provocações. São Bernardo do Campo: SP: Universidade Metodista de São Paulo, 2014. p. 11-12.

COSTA, E. J. Migração e aquisição de Português como Língua de Acolhimento: promovendo a abertura para a diferença e diversidade no Brasil. Anais... V Simpósio de Pesquisa sobre Migrações. Caderno de Resumos. Universidade Federal do Rio de Janeiro (UFRJ), 2017. p. 243 - 248. Disponível em:<https://forumdeimigracaodotorg.files.wordpress.com/2018/07/e-book-v-simpc3adsiodemigrac3a7c3b5es-2017.pdf>. Acesso em: 13 set. 2021.

INSTITUTO FEDERAL DE EDUCAÇÃO, CIÊNCIA E TECNOLOGIA DO RIO GRANDE DO SUL. Projeto Pedagógico do Curso Superior de Licenciatura em Letras - Língua Portuguesa. Bento Gonçalves, 2017. Disponivel em: $<$ https://bento.ifrs.edu.br/site/midias/arquivos/201788105447468ppc_letras_bg_30_05_2017.pdf>.

Acesso em: 12 set. 2021.

SILVA, F. C.; COSTA, E. J. O ensino de Português como Língua de Acolhimento (PLAC) na linha do tempo dos estudos sobre o Português Língua Estrangeira (PLE) no Brasil. Revista Horizontes De Linguística Aplicada. Brasília, v. 19, n. 1, p. 125-143, 2020. https://doi.org/10.26512/rhla.v19i1.24117

Data de submissão: 20/09/2021. Data de aprovação: 25/10/2021. 